\title{
Greetings and Salutations
}

\section{From Gerald Corney}

Previous Medical Geneticist

at the Galton Laboratory in London

For some years there was a joint project between Ian's Department of Obstetrics in Aberdeen and the MRC Human Biochemical Genetics Unit at The Galton Laboratory, University College London to study samples from newborn twins. This led to several extensive family studies subsequently, for which I was responsible. There was excellent co-operation from the families over a wide area both of Aberdeen and the area which surrounds it. This was due, I am sure to Ian's personality which pervaded not only his Department, but also the local General Practitioners and indirectly the families.

\section{From Aldur Eriksson}

Folkhälsan Institute of Genetics, Population Genetics Unit, Helsinki, Finland

I am delighted to have the opportunity of contributing to Ian's Festschrift. I have always felt a great admiration for the soundness of his knowledge and the broad spectrum of his insights into twinning and twins. But I have always also cherished him as one who remains one of the mainstays of the ISTS, indeed our wise Nestor — a Homeric hero famous for his age but mainly for his wisdom.

\section{From Paolo Parisi}

Human Biology Center, Rome University Institute of Movement Sciences (IUSM) and Tor Vergata Department of Public Health, Rome, Italy

I had the privilege of first meeting Ian in the early days of September 1969, as he attended the International Symposium on Twin Studies in Rome, which paved the way to the reorganisation of the area and the development of the International Society for Twin
Studies. That was the first of a long series of meetings, and of a personal relation that grew over the years, giving me the opportunity to increasingly appreciate his profound knowledge and scientific qualities, particularly in the area of twin biology and multiple pregnancy, to which he so much contributed. His leadership in the area, along with his delicate, gentle manners and profound human qualities, made us proud to have him as President of our Society and one of our assets for so many years.

\section{From The Lord Patel \\ Professor of Obstetrics and Gynaecology, Ninewells Hospital, Dundee, and Past President of the Royal College of Obstetricians and Gynaecologists}

It is a great privilege to take part in this Festschrift to Professor Ian MacGillivray - a friend and mentor of many years. Aberdeen and Dundee departments of obstetrics and gynaecology have always had a very close relationship. Ian was always helpful and encouraging whenever we met and inspired me to take an interest in multiple pregnancy and subsequently twins. We both have twins. He continued the great tradition of Scottish obstetrics, particularly obstetric epidemiology.

Ian, thank you for all your help, guidance and friendship.

From Barbara Thompson, OBE

Previously Social Scientist in the Department of Obstetrics and Gynaecology in the University of Aberdeen

My first meeting with Ian was in 1955 and it was about baby-sitting arrangements. He and Edith (sadly now deceased) had just arrived in Aberdeen with their young family - a son and twin daughters. I have many happy memories of their hospi- tality. At the time Ian's research interests were in the physiology and complications of pregnancy but along with all the obstetricians under Dugald Baird, he cooperated in the 'social obstetric' research pursued by the MRC Obstetric Medicine Research Unit of which I was a member.

It was not until Ian returned to Aberdeen as Regius Professor of Obstetrics and Gynaecology in 1965, shortly after I came back from secondment to the MRC Unit in The Gambia, that I became involved in Aberdeen twinning research along with Percy Nylander from Nigeria and Gerald Corney from the Galton Laboratory, London. Thus Ian came to preside over a multi-disciplinary and international study of twinning.

Ian returned to Aberdeen at a crucial time in the development of sociological research. The MRC social scientists formed the nucleus of the new MRC Medical Sociology Unit with Raymond Illsley as Honorary Director. The social aspects of fertility related research continued to be my prime interest with access to obstetric and gynaecological patients and epidemiological analysis. But new ideas and methods of research were introduced as young, confident but inexperienced sociology graduates were appointed. Fortunately Ian accepted these changes with great equanimity and he was unfailingly encouraging and helpful in sustaining the cooperation of his medical colleagues so that studies such as of medical decision-making and observation of clinics could go ahead. It made it easy for me that Ian maintained a liberal policy and supported the development of the Maternity and Neonatal Data Bank.

It has been a pleasure to work with Ian and I am greatly indebted to him for his friendly cooperation over many years. 